Daniel Díez Martinez

Figura 1. Cabecera de The California Architect and Building News, septiembre de 1886.
Doctor Arquitecto por la Universidad Politécnica de Madrid

Profesor en la Universidad Europea de Canarias

\title{
Hacia Arts \& Architecture La revolución editorial de John Entenza (1938-1945)
}

Keywords: Arts \& Architecture, California, Editorial Design, Entenza, Magazines, Typography

In January 1945 Arts \& Architecture launched the Case Study House program, an experiment devised by John Entenza that would reserve for him and his magazine an important place in the history of modern architecture of the twentieth century. From the moment he took over the direction of Arts \& Architecture in 1940, Entenza knew how to seduce creators and artists such as Alvin Lustig, Ray and Charles Eames, Herbert Matter and Julius Shulman, who contributed to raise the graphic standard of his publication and gave it an innovative identity that visually supported the avant-garde intellectual discourse of commitment to modern architecture and design that it defended in its pages. This article analyzes the origins, the strategies of transformation and the proper names that made the magazine a reality that, fifty years after its disappearance in 1967, continues to be as attractive and radical as when it was published. La escena editorial californiana y los ori-
genes de Arts \& Architecture

D esde el nacimiento de la actividad editorial moderna en la segunda mitad del siglo XIX, Nueva York siempre ha ostentando el título de capital mundial de las revistas. Los grandes grupos editoriales de Estados Unidos, como Condé Nast, Time Inc. o McGraw-Hill, al igual que las tres grandes publicaciones de arquitectura estadounidenses del siglo XX, Architectural Record, Architectural Forum y Progressive Architecture, operaban desde sus sedes en el corazón de Manhattan y discurrian estrategias para llegar a los lectores no solo del país, sino del mundo entero. Sin embargo, en el otro extremo, en California, la situación era bastante diferente al frenesí mediático neoyorquino. Las condiciones par- ticulares del estado y su relativo aislamiento con respecto a lo que ocurría en la costa este propiciaron un desarrollo del mundo editorial bien diferente.

La primera revista de arquitectura elaborada en el estado de California fue The California Architect and Building News y se publicó entre 1880 y 1900 (figura 1). Era una publicación con sede en San Francisco y dependía de dos órganos oficiales de representación de la profesión de arquitecto a escala local: la Pacific Coast Association of Architects y la sucursal del American Institute of Architects en San Francisco. Los primeros números exhibían un aspecto más propio de un diario de noticias que de una publicación especializada en arquitectura y sus contenidos se centraban en artículos de interés práctico para el ejercicio de la profesión, además de algunos

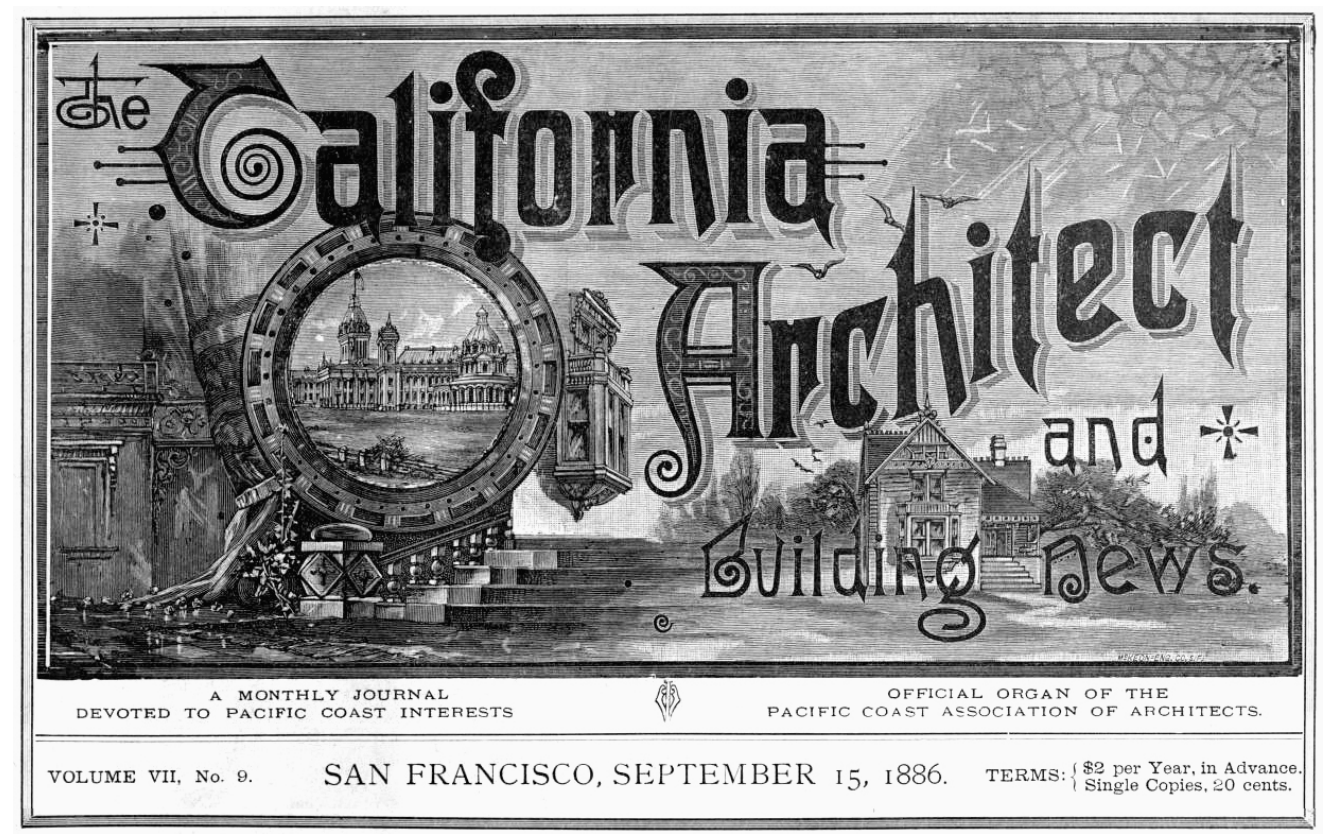



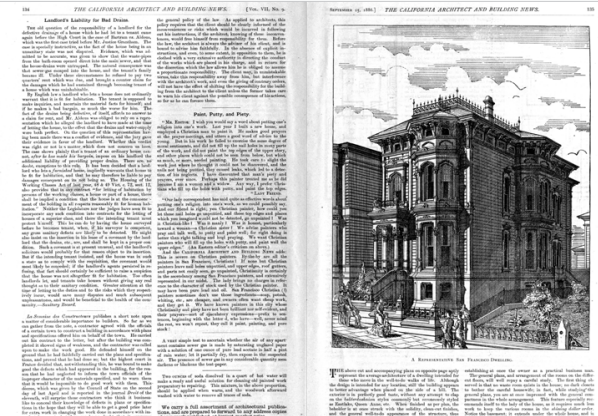

otros que trataban temas referidos al sector agrario, tan importante en California. Con el tiempo, sin embargo, evolucionó hacia una maqueta más legible y atractiva, en la que se reservaba multitud de espacio para la introducción de fotografias y dibujos de proyectos de la costa oeste estadounidense, con especial predilección por la arquitectura residencial victoriana del área de la bahía de San Francisco (figura 2). Otra de las primeras publicaciones surgidas en California que adquirió cierta repercusión local fue The Architect \& Engineer of California, que comenzó a publicarse en 1905, ${ }^{1}$ también desde San Francisco, con una apuesta gráfica muy interesante, especialmente gracias a la potencia visual de sus portadas (figura 3), pero con una linea editorial bastante conservadora en lo que a contenidos de arquitectura se refiere.

Para trazar los orígenes de Arts \& Architecture debemos remitirnos a dos publicaciones diferentes: The Pacific Coast Architect, dedicada a la arquitectura de la costa oeste de Estados Unidos; y California Southland, una revista multidisciplinar que tenía como eje conductor la puesta en valor de la buena vida

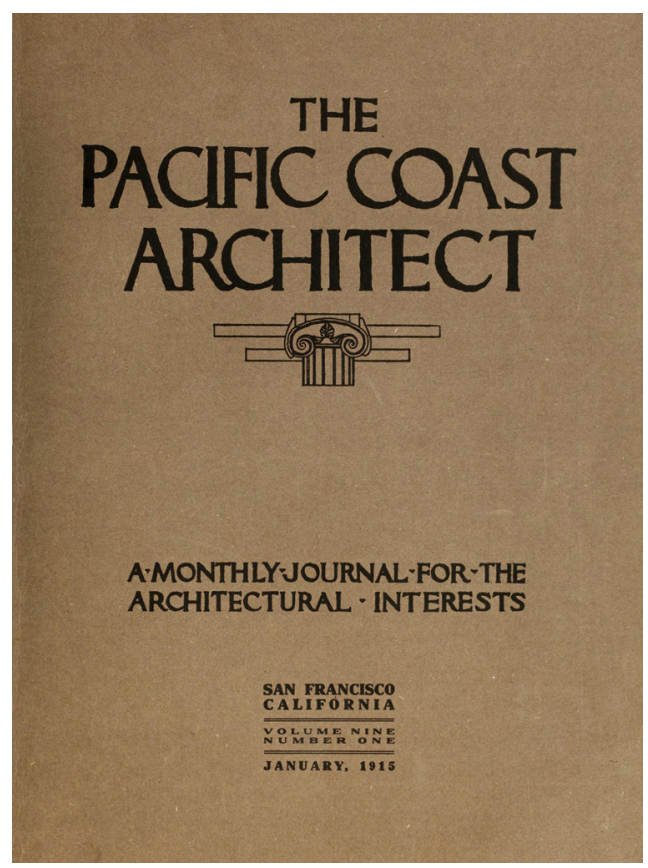

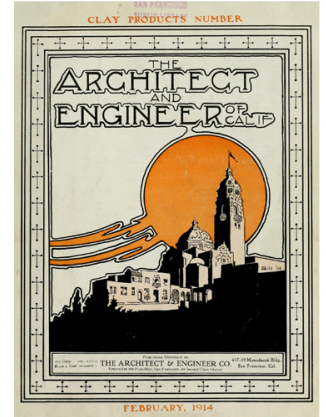
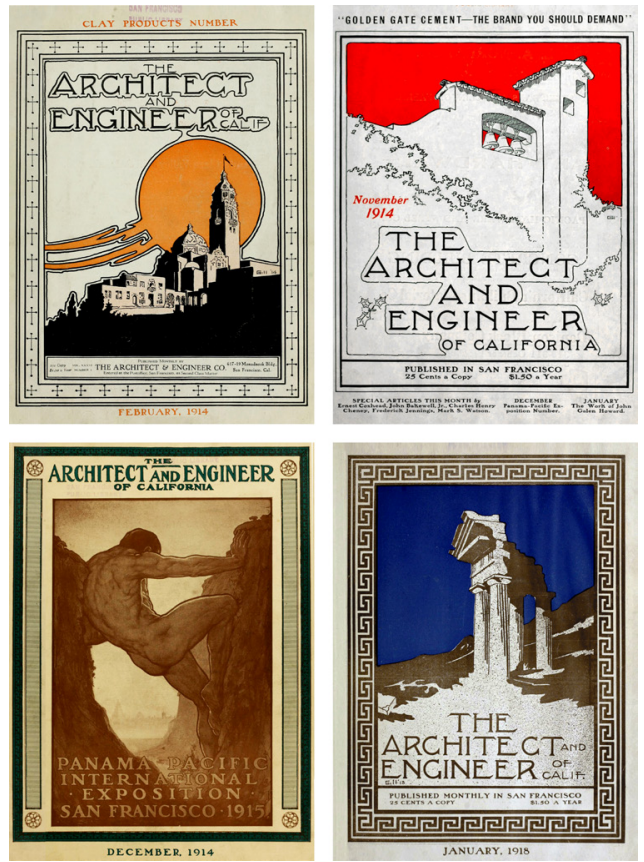

del sur de California. The Pacific Coast Architect (figura 4) se fundó en abril de 1911 en Portland, Oregón, aunque en febrero de 1914 trasladó su sede a la ciudad de San Francisco para convertirse en la publicación oficial de la sucursal del American Institute of Architects en California, que había dejado de editarse en 1900, tal como anunciaba en su editorial de aquel mismo número (TPCA 1914, p. 7). Sin embargo, The Pacific Coast Architect no tenía nada que ver con su predecesora en la función, y a pesar de los cambios de sede, de grupo editorial y de nombre, ${ }^{2}$ se mantuvo siempre fiel a un tipo de publicación en la cual se le concedía más importancia al apartado gráfico que al texto, al que apenas se le dedicaban unas pocas páginas al principio y al final de cada número. De hecho, el propio índice reflejaba esta realidad, y aparecía dividido en dos bloques generales: contenidos e ilustraciones. Asi, The Pacific Coast Architect se presentaba como una especie de catálogo de edificios, que aparecían documentados en el cuerpo central con información gráfica abundante: planos, dibujos y fotografias a toda página reproducidas con una calidad excelente. Con respecto a la selección de los edificios que aparecian documentados, no parece que existiera un criterio definido. Las páginas de The Pacific Coast Architect combinaban indistintamente grandes edificios públicos $\mathrm{y}$ corporativos junto a pequeñas residencias unifamiliares, aunque con el denominador común de que la arquitectura publicada se enmarcaba dentro de los estilos historicistas imperantes en las décadas de 1910 y 1920 en California (figura 5).
Figura 2. "A representative San Francisco dwelling". The California Architect and Building News, septiembre de 1886, pp. 134-135.

Figura 3. Varias portadas de The Architect $\&$ Engineer of California correspondientes a los números de febrero de 1914, noviembre de 1914, diciembre de 1914 y enero de 1918.

Figura 4. Portada de The Pacific Coast Architect, enero de 1915. 
Figura 5. Varios edificios tal como se publicaron en las páginas centrales de The Pacific Coast Architect: Federal Realty Building en Oakland, de Benjamin Geer McDougall (enero de 1915); conjunto de la Panama-Pacific International Exhibition de San Francisco, de George William Kelham (febrero de 1915); Merchants National Bank Building en Los Ángeles, de William Curlett \& Son (abril de 1915); Residence W. T. Sesnon en Soquel, California, de Ward \& Blohme (julio de 1913).

Figura 6. California Southland tenía una linea editorial muy variada. En un mismo pliego se podía encontrar un artículo sobre arquitectura residencial de estilo colonial español y otro sobre la boda de una familia de la burguesía de Los Ángeles. California Southland, abril de 1920, pp. 16-17.

Figura 7. Portada de California Southland, marzo de 1925.
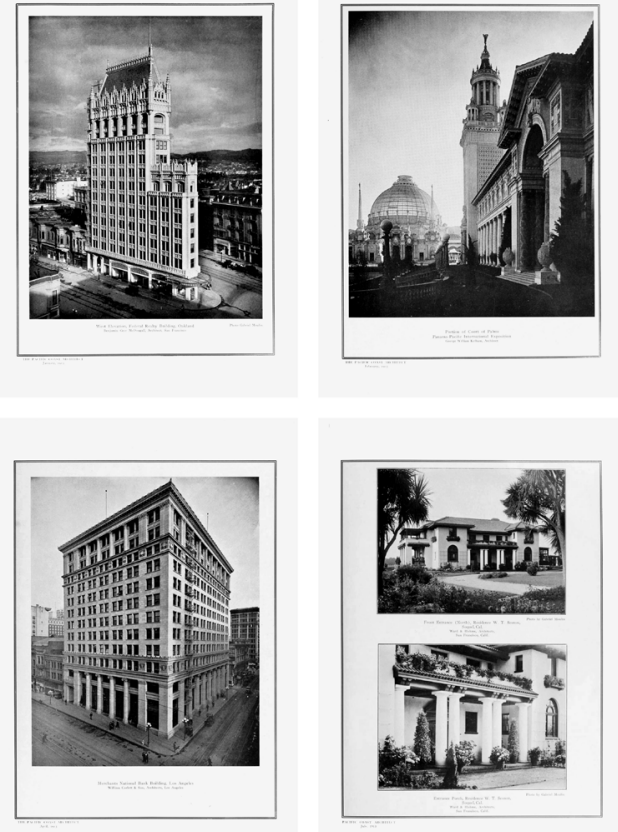

Por su parte, California Southland publicó su primer número en agosto de 1918 desde su sede en Pasadena, junto a Los Ángeles. En un principio, se presentaba como una publicación con unos contenidos muy eclécticos en la que todo tema minimamente relacionado con el sur de California parecía tener cabida. Así, se publicaban artículos sobre la vida universitaria local, turismo y hostelería, técnicas de jardineria, la industria de conservas de frutas, exposiciones de arte, poesía, las últimas tendencias de moda femenina y masculina, información acerca de promociones inmobiliarias locales y noticias de sociedad en las cuales se podía leer acerca de las fiestas que la burguesía de Pasadena y Los Ángeles celebraba en prestigiosos clubes de campo (figura 6). El tono general de aquellos primeros números evidenciaba que se dirigia a un

público culto y hedonista, muy en la línea del entendimiento de la vida que se le atribuye a la élite cultural del sur de California de los felices años veinte. Con el tiempo, la revista fue mutando hacia posiciones editoriales más cercanas a las de una shelter magazine, ${ }^{3}$ tal como anunciaba en su portada, en la cual podia leerse "California's Home and Garden Magazine" ("la revista del hogar y el jardín de California"), asi que los temas relacionados con la arquitectura residencial, la decoración interior, el paisajismo y la vida al aire libre cobraron cada vez más relevancia. En lo que al aspecto se refiere, California Southland concedía un peso específico importante a su aparato gráfico. La revista presentaba una maqueta muy atractiva, en la que imágenes y texto estaban perfectamente integradas en un producto editorial uniforme. Otro aspecto llamativo eran sus portadas, que solian remitir a visiones paradisiacas de inspiraciones mediterráneas de los paisajes del sur de California (figura 7). A veces se utilizaban fotografias parcialmente coloreadas, y otras veces eran reproducciones de óleos a todo color, lo que le otorgaba un aspecto lujoso que conectaba muy bien con el público al que se dirigía.

\section{Aleaciones editoriales para una apuesta moderna}

Siguiendo el patrón característico de fusiones de los años veinte y treinta, la editorial Western States Publishing Company adquirió The Pacific Coast Architect y California Southland y las combinó para dar lugar a

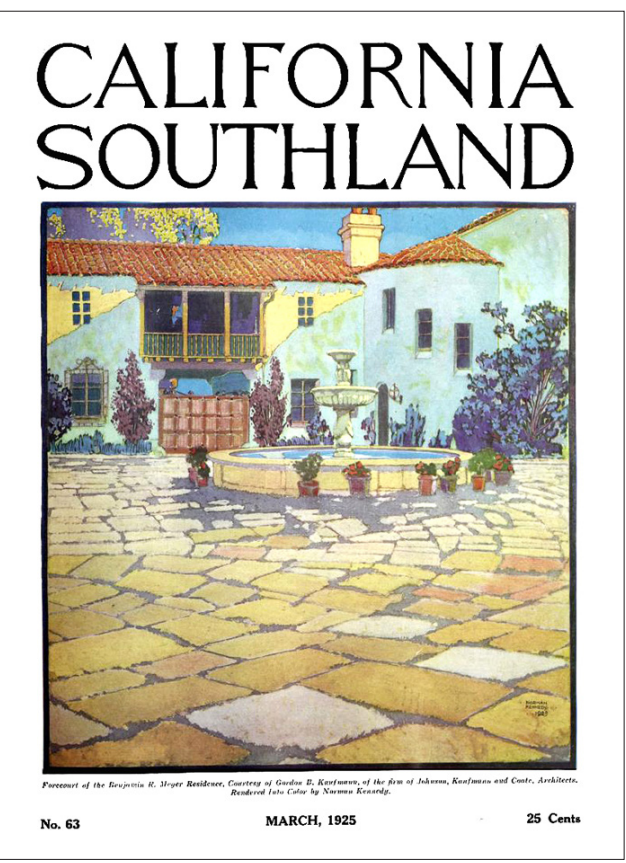




\section{California Arts E Architecture combining \\ Pacific Coast Architect California Southland

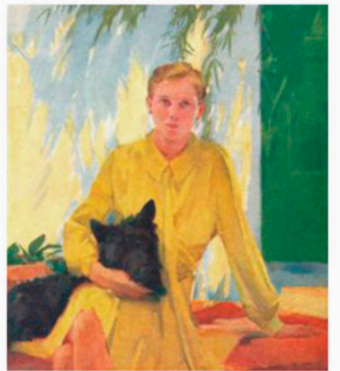 \\ February 1929 \\ 35 a copy \\ 3.․o year}

una nueva publicación. El resultado de aquella mezcla improbable, que debía fusionar la publicación oficial del American Institute of Architects en la costa oeste con una revista de contenidos eclécticos dirigida a la élite social del sur de California de los felices años veinte, fue California Arts \& Architecture, cuyo primer número se publicó en febrero de 1929 (figura 8).

La recién nacida desarrolló una personalidad editorial propia que bebía de sus predecesoras. En cuanto a su diseño gráfico, seguía la estela marcada por California Southland y apostaba, desde su primer número, por una maqueta cuidada y unas portadas muy potentes, con un gran valor pictórico (figura 9), que le diferenciaban del resto de publicaciones de arquitectura del momento. En cuanto a contenidos, California Arts \& Architecture recogía el testigo de Pacific Coast Architect y se posicionaba como la revista encargada de dar visibilidad a la arquitectura que se estaba construyendo en California, prestando especial atención al espacio doméstico. No por casualidad, el grupo editorial propietario había nombrado editor jefe a Harris Allen, un reputado miembro del American Institute of Architects con una amplia experiencia en arquitectura residencial en la zona de la bahía de San Francisco (Thompson 2006), quien a su vez atrajo como colaboradores habituales a arquitectos de la escena de Los Ángeles igualmente especialistas en vivienda, tales como Roland Coates, Sumner Spaulding, Ralph Flewelling o Wallace Neff. Al igual que habia sucedido con California Southland, la nueva California Arts \& Architecture daba absoluta prioridad al espacio doméstico, y siempre
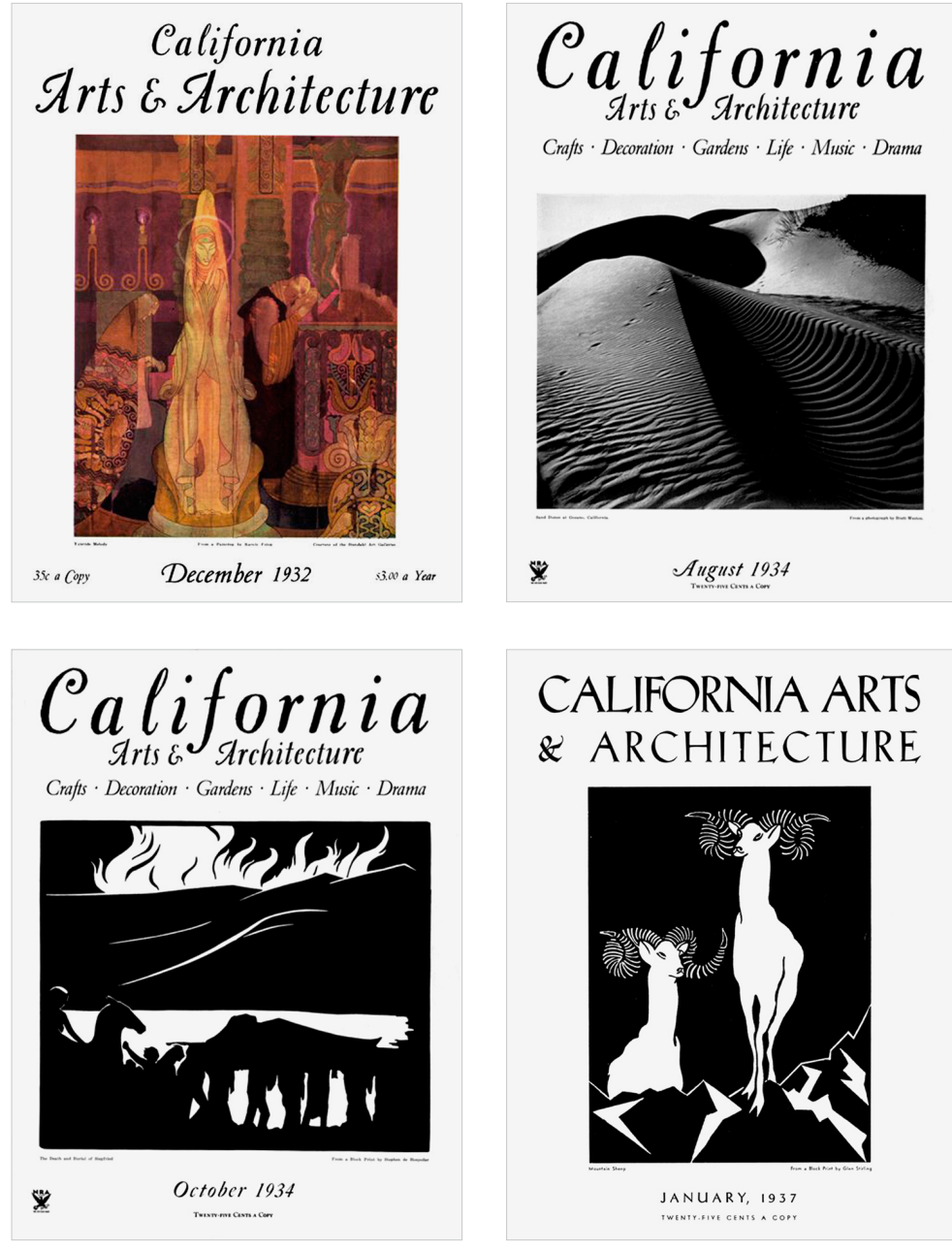

CALIFORNIA ARTS \& ARCHITECTURE

había hueco en sus páginas para publicar alguna residencia unifamiliar de estilo Tudor, Colonial Español, Georgiano, Mediterráneo o cualquiera de los otros lenguajes de inspiración historicista que se enmarcaban dentro del amplio y ecléctico abanico estilístico de la arquitectura residencial de California del momento. La revista también dejaba lugar, aunque en mucha menor medida, para los grandes proyectos Art Déco que estaban poblando el centro de Los Ángeles, como la Richfield Tower (Los Ángeles, 1928-1929) diseñada por el arquitecto Stiles O. Clements, el edificio Bullocks Wilshire (Los Ángeles, 1929), de John y Donald Parkinson, o el edificio Eastern Columbia (Los Ángeles, 1930), de Claud Beelman.

La arquitectura moderna, en un primer momento relegada a una posición casi anecdótica, fue ganando presencia conforme avanzaba la década de 1930. El punto álgido llegó en enero de 1935, cuando California Arts \& Architecture publicó "el primer ejemplar de una revista californiana que se dedicaba integramente a la arquitectura moderna" (Crosse 2010a). Aquel número incluía varios
Figura 8. Portada del primer número de California Arts \& Architecture, publicado en febrero de 1929.

Figura 9. California Arts \& Architecture acudía con frecuencia a la reproducción de obras de arte para ilustrar sus portadas: "Yuletide Melody" de Karoly Fulop (diciembre de 1932); "Dunes, Oceano" de Brett Weston (agosto de 1934); "Ring of the Nibelung 10 woodcuts: Death and Burial of Siegfried" de Stephen de Hospodar (octubre de 1934); "Mountain Sheep" de Glen Stirling (enero de 1937). 
Figura 10. "Modern house for the desert" ("Una casa moderna para el desierto"). La casa Davidson (Palm Springs, 1936), de Eric Webster y Adrian Wilson fue uno de los primeros edificios de arquitectura moderna al que California Arts $\&$ Architecture le dedicó una portada (octubre de 1936).
Figura 11. John D. Entenza (1905-1984), hacia 1940.

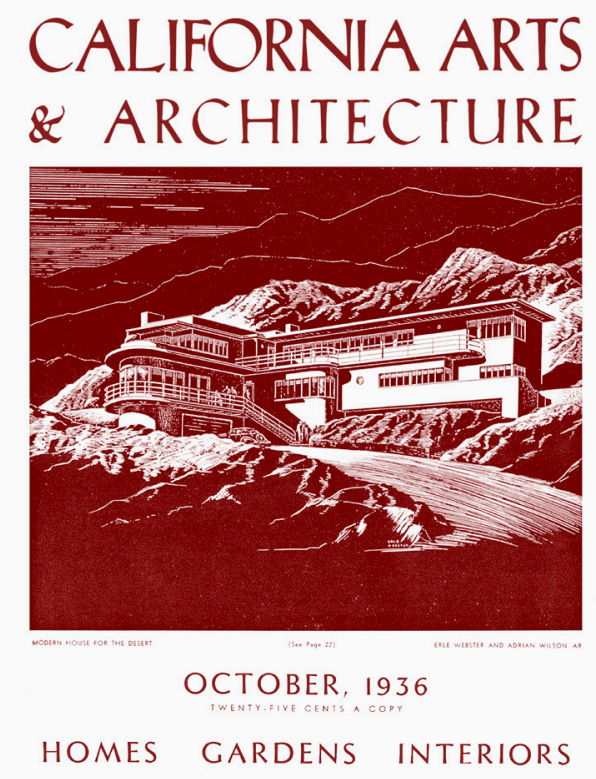

proyectos de viviendas diseñadas por Richard Neutra, Rudolph Schindler y otros arquitectos modernos, ${ }^{4}$ así como un artículo tributo a Frank Lloyd Wright escrito por Pauline Schindler, esposa del arquitecto. El recientemente nombrado editor jefe de aquel número, George Oyer, escribía en su editorial:

Desde hace algunos meses hemos estado considerando si era conveniente publicar algo del trabajo de nuestros diseñadores modernos de California. El término 'moderno', cuando se utiliza para hablar de arquitectura y en decoración de interiores, tiene un significado un tanto vago. Para los profanos, el término moderno se aplica a cualquier casa o edificio con lineas horizontales o verticales dominantes [...]. Realmente es imposible mostrar todos los proyectos de nuestros mejores arquitectos modernos. Por eso, queremos agradecer a la señorita Pauline Schindler su ayuda en la selección de fotografias y artículos. Te guste o no, no es nuestro problema. Es arquitectura de California, asi que le estamos agradecidos. (Oyer 1935)

A pesar de la torpeza a la hora de definir qué significaba realmente la etiqueta "moderno" cuando se aplicaba a la arquitectura, el tono un tanto desafiante del editor dejaba claro que tenía intención de adquirir cierto compromiso con los arquitectos modernos californianos, aunque solo fuera por el hecho de estar ejerciendo la profesión en casa (figura 10). Tal como sostiene la gran historiadora y crítica de la arquitectura californiana Esther McCoy (1984: 42), "aquel pequeño grupo de primeros [arquitectos] modernos fue afortu- nado de que existiera una revista como California Arts \& Architecture, que publicaba sus proyectos".

Sin embargo, si bien la arquitectura constituía el tema principal de los contenidos, California Arts \& Architecture también reservaba un espacio para otras disciplinas artísticas transversales, como había hecho antes California Southland, así que en todos los números se incluía algún artículo sobre pintura, escultura, mobiliario, diseño de interiores, fotografia, música, paisajismo, teatro o cine. ${ }^{5}$ California Arts \& Architecture era una publicación extraña, en cierto modo inclasificable, que se movia con desparpajo y espíritu vanguardista en un terreno intermedio entre la revista de arquitectura que había sido Pacific Coast Architect y la shelter magazine que habia sido California Southland. Por supuesto, aquel experimento no pasó desapercibido para John Entenza, un amante del arte abstracto y de la arquitectura y el diseño de vanguardia con espiritu altruista que buscaba desesperadamente una tribuna para promocionar la producción artística local.

\section{E1 huracán Entenza}

John D. Entenza (Calumnet, Michigan 1905 - La Jolla, California, 1984) (figura 11) es el personaje más influyente en la historia de California Arts \& Architecture. Del mismo modo que editores como Alfred Lawrence Kocher y Douglas Haskell le imprimieron su propia identidad a Architectural Record y Architectural Forum respectivamente, Entenza convirtió California Arts \& Architecture en una extensión de su personalidad y de su

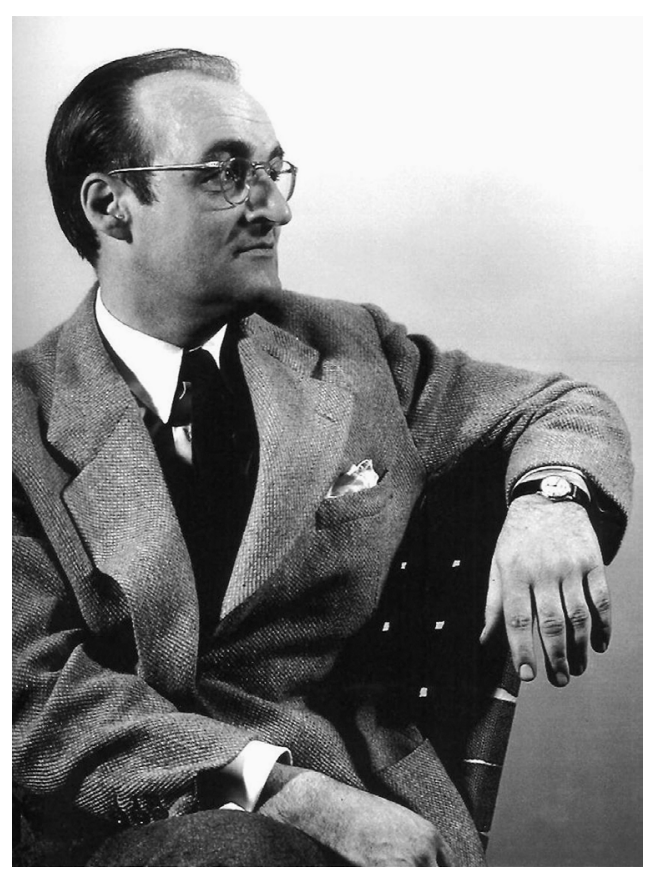


manera de entender la arquitectura y el diseño modernos. Él fue su propietario, pero también su director, editor jefe, articulista habitual y, fuera de la oficina, su mejor relaciones públicas. Durante más de veinte años, Entenza dedicó todo su esfuerzo para que la revista sirviera como plataforma para "situar California en el mapa cultural estadounidense y se identificara con un estilo de vida y el gusto por el diseño más avanzado del país" (Votolato 1998: 54).

John Entenza adquirió California Arts \& Architecture en 1938, ${ }^{6}$ aunque no fue hasta dos años después, en febrero de 1940, cuando asumió el cargo de editor jefe y su nombre apareció por primera vez en la plantilla de la revista. ${ }^{7}$ A partir de aquel momento, Entenza sumió California Arts \& Architecture en un vertiginoso proceso de trasformación que traería cambios sustanciales en un periodo de tiempo muy corto.

Ya desde aquel primer número de febrero de 1940, el recién autoproclamado editor jefe y director de California Arts \& Architecture se aseguró una tribuna propia, para lo cual creó "Notes in passing", una sección fija mensual que le concedia una página entera para plasmar libremente sus ideas y reflexiones sobre arte, política, diseño industrial o, por supuesto, arquitectura. Para el número siguiente de marzo de 1940, Entenza encargó el diseño de una nueva tipografia para la cabecera ${ }^{8} \mathrm{y}$ mandó incluir en la portada el dibujo de una sección transversal de la casa Weston Havens (Berkeley, 1940) de Harwell Hamilton Harris (figuras 12 y 13), un arquitecto radicalmente moderno que había trabajado en el estudio de Richard Neutra y al que tres años antes Entenza habia encomendado el proyecto de su propia casa en Santa Mónica (figura 14): una vivienda pequeña, típicamente moderna, cuyo máximo protagonismo formal se lo llevaba un "muro curvo de madera contrachapada que ofrecía una transición suave entre el jardin exterior y el salón de la casa" (CA\&A 1938), tal como se recogía en un artículo dedicado a la obra publicado en California Arts $\&$ Architecture. La decisión de poner en portada un proyecto de este mismo arquitecto no respondia, por tanto, a un tema de interés informativo, sino que evidenciaba la fascinación que John Entenza sentía por la arquitectura moderna y su deseo de convertir aquella revista en una prolongación de su arrolladora personalidad.

Además de estos primeros cambios de indole editorial, Entenza también emprendió reformas de carácter empresarial y de

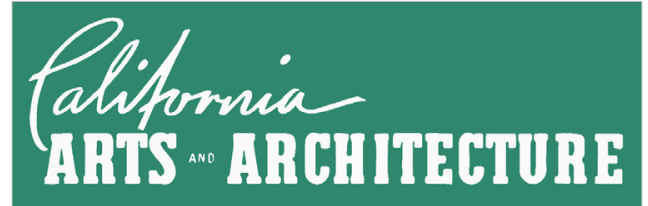

Figura 12. Portada del segundo número de California Arts \& Architecture con John Entenza como editor jefe en la que figura una sección transver-

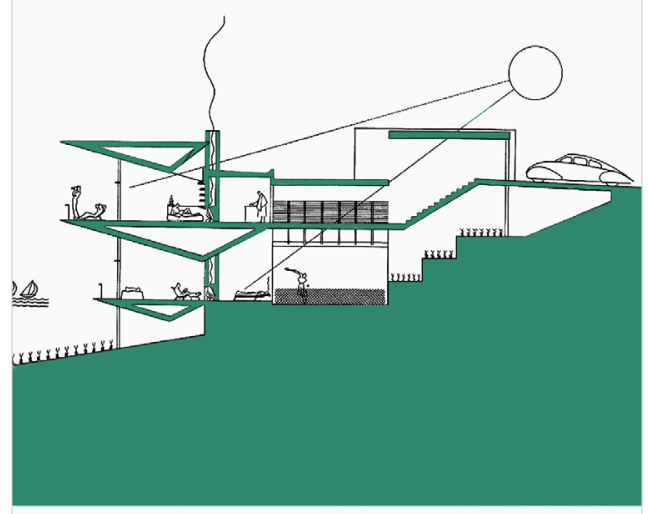

MARCH

1940 sal de la casa Weston Havens (Berkeley, 1940) de Harwell H. Harris.

Figura 13. Exterior de la casa Weston Havens (Berkeley, 1940) de Harwell H. Harris. Fotografia: Man Ray, 1941.

Figura 14. Exterior de la John Entenza Residence (Santa Mónica, 1937) de Harwell Hamilton Harris. Fotografia: Michael W. Folonis, 2016.
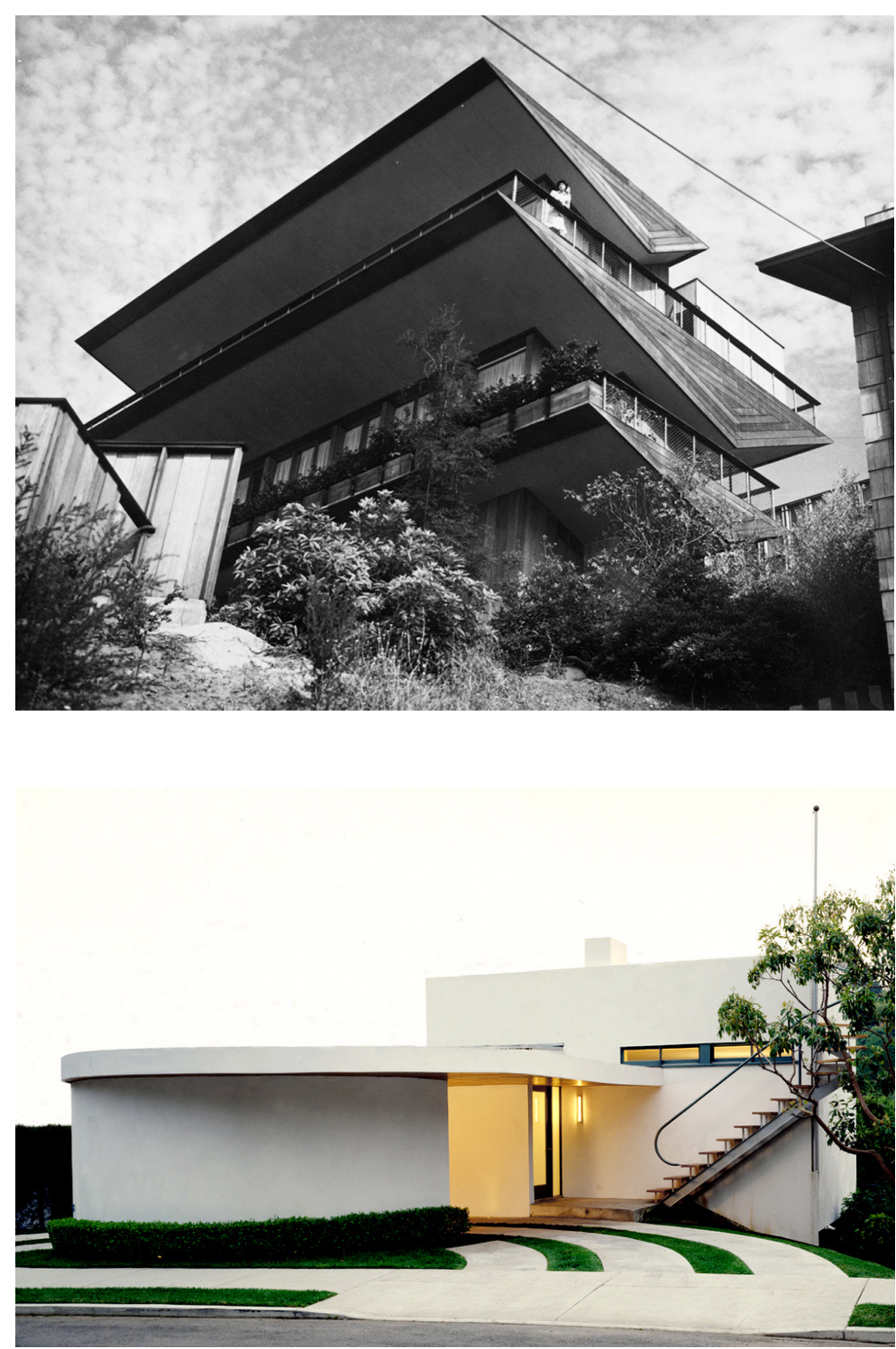
gestión interna. La nómina de miembros del consejo editorial y la plantilla de trabajadores variaban rápidamente número tras número y en agosto de aquel mismo 1940 Entenza trasladó la sede a una nueva oficina situada en el 3305 de Wilshire Boulevard, en pleno corazón de Los Ángeles. Aquel movimiento culminaba una serie de acciones que había llevado a cabo en solo siete meses, una auténtica revolución que el historiador John Crosse (2010a) compara con "un animal marcando su territorio y diciéndole al mundo que estaba preparado, dispuesto y capacitado para asumir el control [de California Arts \& Architecture], no solo como editor jefe, sino también como director, y lo más rápidamente posible".

\section{Trabajo en equipo}

Los cambios que el flamante director de California Arts \& Architecture había emprendido desde su llegada en febrero de 1940 no eran más que un pequeño adelanto de lo que estaba por llegar. Entenza tenía grandes planes para su revista, y para llevarlos adelante era consciente de que sería fundamental rodearse de figuras con talento. Entenza era un personaje poderoso e influyente a nivel local y también nacional, un maestro en las relaciones personales con un gran poder de persuasión que utilizó para seducir y captar a los mejores y ubicarlos bajo su protección en aquel coto privado que era California Arts \& Architecture (Goldstein 1990). Así, supo atraer artículos firmados por personalidades con calado del mundo del arte y de la arquitectura, como Man Ray, Walter Gropius, Lewis Mumford, Richard Neutra o Edgar Kaufmann, Jr., por citar solo unos pocos. Además, desde enero de 1943, incorporó como socio editor a un amigo personal de Entenza, Peter Yates, un erudito capaz de "escribir con profundidad intelectual y fervor sobre cualquier cosa desde la música de John Cage o Charles Ives, hasta la pintura de Philip Guston, el arte maya o las cuestiones sociales que siguen afectándonos hoy" (Travers 2008).

Entenza se sirvió de su gran poder de persuasión para convertir la revista en el reducto de un selecto grupo de arquitectos, artistas y críticos con sensibilidad moderna, en una especie de club privado con derecho de admisión al que solo podía acceder "todo aquel que era 'alguien' en la escena vanguardista de mediados de siglo de Los Ángeles" (Smith 1989: 146). Una de las primeras incorporaciones importantes fue la del matrimonio de Charles Eames (Saint Louis, Missouri, 1907 - Saint Louis, Missouri, 1978) y Ray Eames
(Sacramento, California, 1912 - Los Ángeles, 1988). En 1941 los Eames habian abandonado la Cranbrook Academy of Art en Detroit para instalarse en Los Ángeles, atraídos por el clima de experimentación artística que respiraba la ciudad (Kirkham 1995: 52). La pareja de diseñadores representaba a la perfección el tipo de sensibilidad funcionalista y racional pero a la vez hedonista y sensual que Entenza queria transmitir en California Arts \& Architecture, por lo que tan pronto se establecieron en la ciudad, empezaron a colaborar y a trabajar juntos. Charles Eames debutó en septiembre de 1941 con un artículo ilustrado con fotografias del trabajo de sus estudiantes de Cranbrook en el que exponía su visión acerca del cometido del diseñador en la sociedad contemporánea:

Trabajar en relación con una disciplina como la economía, en cuanto a materiales y formas se refiere, es algo saludable para los diseñadores, ya que les enseña a desarrollar una sensibilidad natural para determinar qué es necesario y qué no [...]. Cuando uno ve un avión, siente que esas formas aerodinámicas se adecúan a su función, por lo que aún sin saber mucho sobre aeronáutica, el diseño nos parece bueno. Este efecto es muy diferente al que nos producen estas mismas formas cuando aparecen en una aspiradora o en un tintero, donde el diseñador se ha dejado llevar por la potencia de la forma y ha caido en el error de pensar que es bueno darle un aspecto aerodinámico a todo. La gente reconoce instintivamente el buen diseño de un velero, un hacha, un avión o una presa $y$, consciente o inconscientemente, obtiene de ellos un sentimiento de satisfacción estética. [En el diseño moderno] no hay lugar para la simulación, el esnobismo o para juzgar los resultados por el alto precio de los materiales utilizados. (Eames 1941: 15)

Así, mientras Charles contribuía a la creación del discurso intelectual con artículos en los que abordaba los grandes retos a los que los que los arquitectos de la modernidad debían dar respuesta, Ray jugó un papel relacionado con el discurso visual y se centró en las portadas: entre abril de 1942 y diciembre de 1944, diseñó el 80\% de las portadas, es decir, veintiséis de los treintaitrés números que se publicaron. Las portadas de Ray Eames consistian en unas composiciones abstractas repletas de color, texturas y formas que recogían la influencia de artistas de vanguardia como Hans Hofmann, Joan Miró, Hans Arp o Alexander Calder (figura 15). La diseñadora 

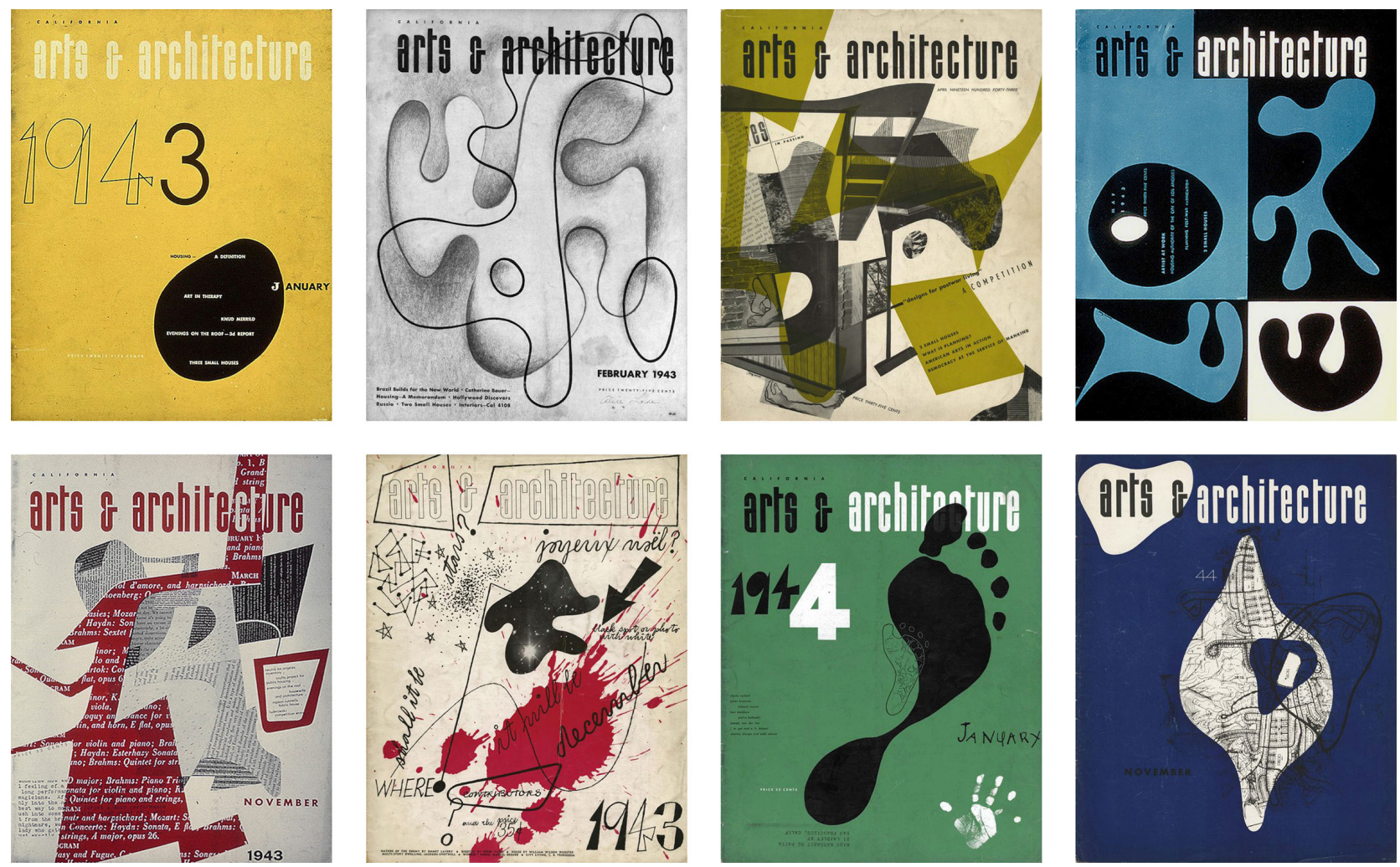

explicaba sus motivaciones artísticas en un artículo publicado en septiembre de 1943:

Mi interés por la pintura radica en el redescubrimiento de la forma a través del movimiento $y$ del equilibrio entre la profundidad y la luz. El uso de este medio tiene que servirme para recrear un orden satisfactorio de mis experiencias de este mundo. Deseo, ante todo, aumentar nuestro placer, ampliar nuestras percepciones y enriquecer nuestras vidas. (Eames 1943: 16)

Entenza reconoció el valor de la aportación de los Eames, por lo que decidió nombrar a Charles socio editor y a Ray miembro del Consejo Editorial desde el número de mayo de 1942. ${ }^{9}$ La buena relación profesional que se fraguó entre los Eames y John Entenza dio paso a una amistad verdadera, hasta el punto en que en 1945 compraron terrenos contiguos en Pacific Palisades para construir sus respectivas casas (figura 16), que se enmarcarian dentro del programa Case Study House. Los Eames diseñaron su propia vivienda, la Case Study House número 8, y colaboraron con Eero Saarinen en el diseño de la casa de Entenza, la Case Study House número 9. Sin embargo, la convivencia duró poco. Según apunta Crosse (2010a), el matrimonio y Entenza se enemistaron después de una fuerte discusión que tuvo lugar en 1951, así que el editor se mudó a otro barrio, puso su casa a la venta, eliminó a los Eames de la plantilla de Arts \& Architecture y nunca más volvió a hablarse con ellos.

Después de los Eames, le llegaría el turno al fotógrafo Julius Shulman (Brooklyn, Nueva York, 1910 - Los Ángeles, 2009). Cuando Entenza se hizo cargo de la revista, Shulman ya era un personaje popular en la escena arquitectónica y vanguardista de Los Ángeles. Su carrera como fotógrafo de arquitectura había comenzado en 1936, cuando Richard Neutra le nombró fotógrafo oficial de sus construcciones después de ver las instantáneas que había tomado con una cámara de bolsillo de

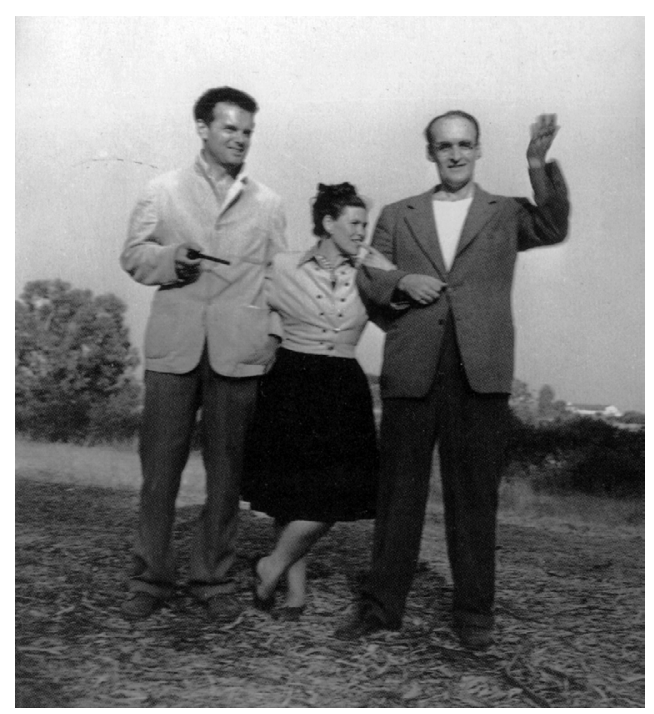

Figura 15. Algunas de las portadas que Ray Eames diseñó para California Arts \& Architecture entre abril de 1942 y diciembre de 1944 .

Figura 16. Charles y Ray Eames junto a John Entenza en el terreno donde construirian sus viviendas, Pacific Palisades, 1945. 
Figura 17. Julius Shulman y Richard Neutra en la sesión de fotos de la casa Tremaine, en Montecito, California, en 1948.

Figura 18. La primera portada de California Arts \& Architecture que utilizaba una fotografía de Julius Shulman fue la de enero de 1940 , en la que figuraba una imagen de la casa Rosenson (Los Ángeles, 1940) de Paul Laszlo.

Figura 19. Las fotografías de Julius Shulman cambiaron la manera de publicar edificios en Arts \& Architecure, y las imágenes desplazaron por completo al texto. En la imagen, una doble página del reportaje de la casa Entenza o Case Study House número 9 (Pacific $\mathrm{Pa}$ lisades, 1945-49), de Charles Eames y Eero Saarinen, tal como se publicó en Arts \& Architecure, julio de 1950, pp. 38-39.

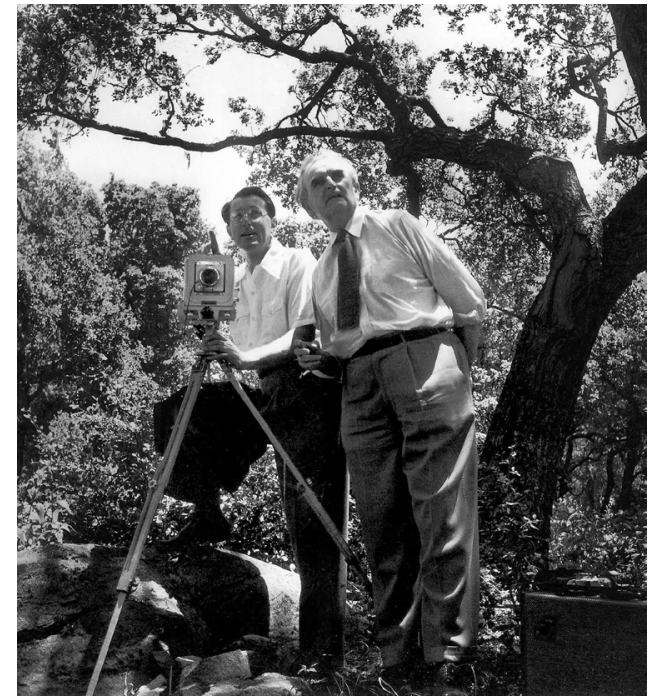

su recién finalizada casa Kun en Los Ángeles (figura 17). ${ }^{10}$ Desde aquel momento, todos los arquitectos modernos de California querian que Shulman fotografiara su obra. El fotógrafo dominaba el lenguaje anguloso y transparente de la arquitectura que retrataba, por lo que la capacidad de expresión arquitectónica de sus fotografias las convertía en documentos idóneos para la prensa especializada.

De hecho, cuando John Entenza decidió integrarlo en la plantilla fija en el número de diciembre de 1942, Shulman ya llevaba un tiempo trabajando esporádicamente para California Arts \& Architecture (figura 18). Sin embargo, su incorporación a la nómina de colaboradores habituales trajo consecuencias importantes, fundamentalmente dos. Por un lado, eran instantáneas muy atractivas y potentes, que hacian gala de unos estándares

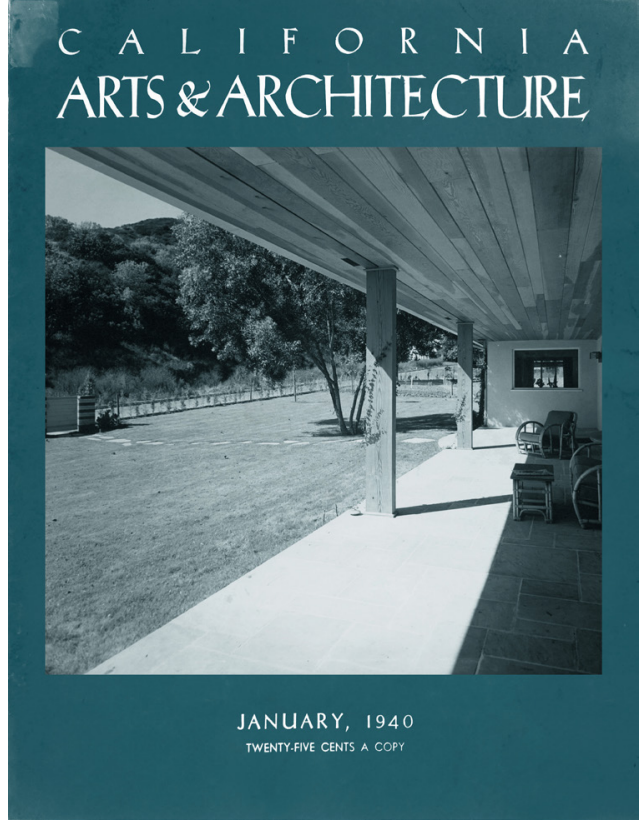

de composición y técnica exquisitos, por lo que su inclusión ayudaba a elevar el estándar gráfico de la publicación. Pero además, Shulman fue especialmente habilidoso en desarrollar una particular "utilización de la luz y de la sombra que le servía para delinear la forma y la estructura de los edificios" (Elwall 2000: 46), algo que convirtió sus imágenes en una herramienta muy útil en la tarea de revelar las cualidades formales y espaciales de los proyectos retratados. Este tipo de fotografía cambió el modo en que California Arts \& Architecture iba a plantear los reportajes sobre un edificio en concreto, donde las fotografias y los planos ganaban espacio al texto (figura 19). En palabras de David Travers (2008), edi-

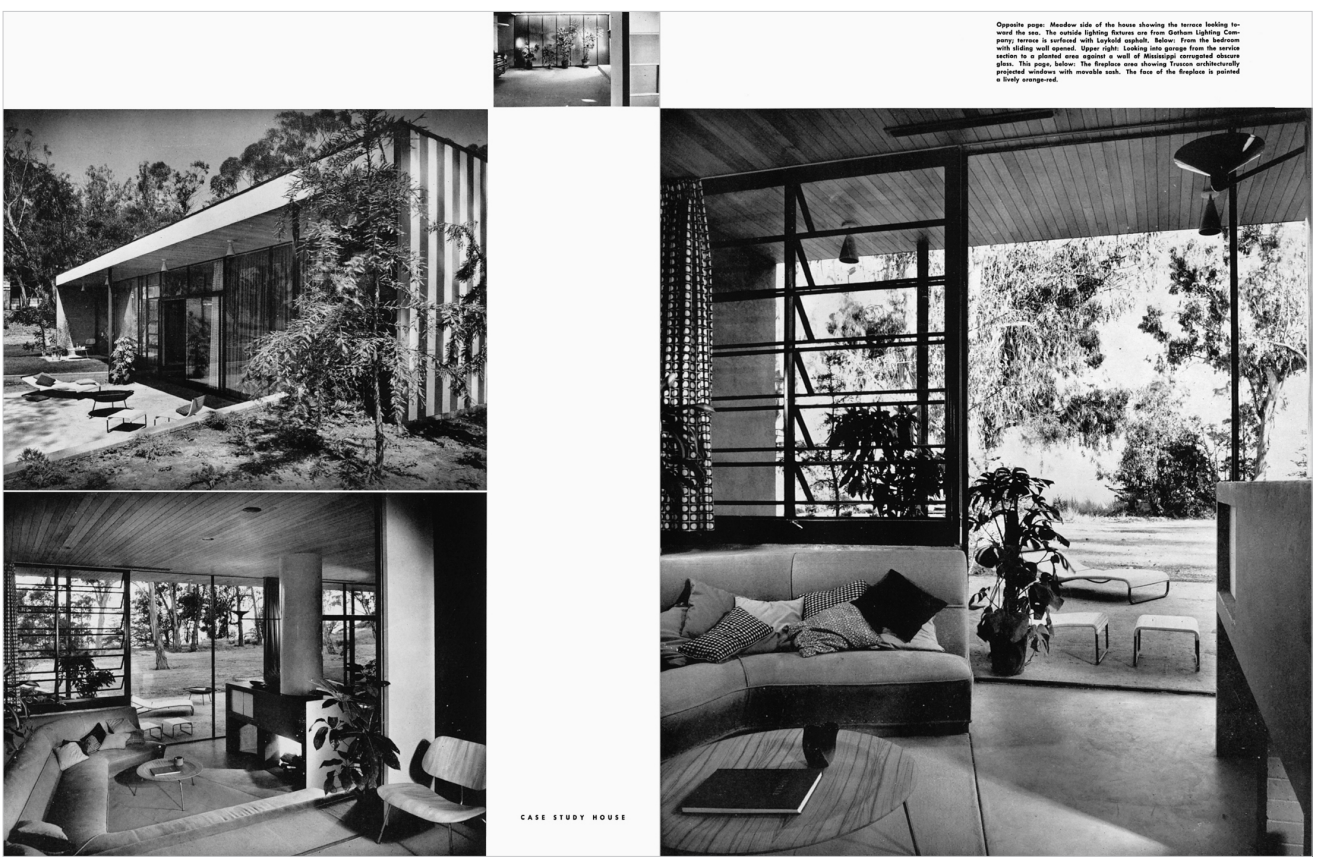




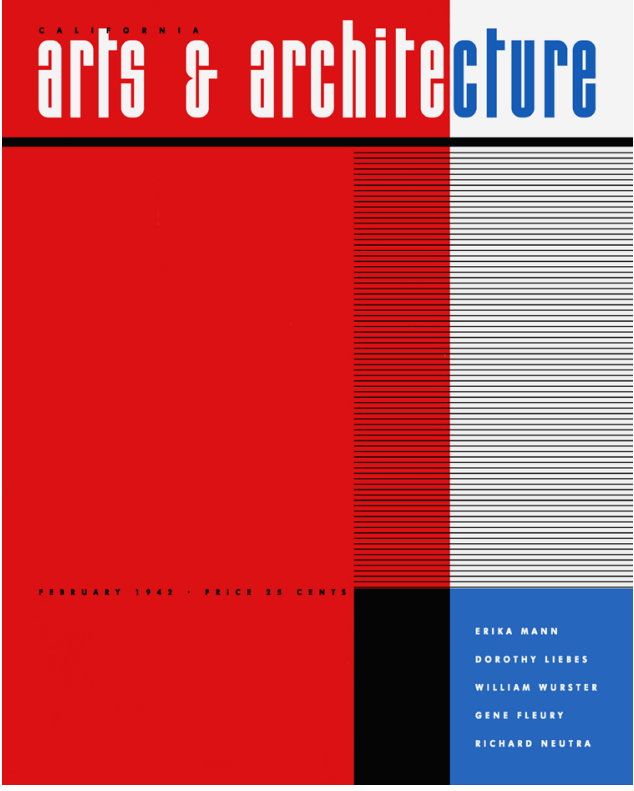

tor de la revista durante sus últimos años de existencia, entre 1962 y 1967:

La politica de Arts \& Architecture consistía en presentar los proyectos de arquitectura sin ningún análisis crítico de acompañamiento. Los edificios que se publicaban tenian que ser capaces de hablar por si mismos, por lo que cualquier texto explicativo se limitaba a una breve exposición del arquitecto, por lo general sobre la base de una descripción breve del programa y algún aspecto constructivo.

Una imagen, si era de Shulman, valía más que mil palabras.

\section{El efecto Lustig}

Además de la fotografía de Shulman, uno de los aspectos visuales más distintivos y llamativos de la revista fueron sus portadas, un aspecto que, de hecho, se remontaba hasta los tiempos de California Southland. Sin embargo, Entenza quería llevar esta estrategia un paso más allá. Para el editor, la portada era un elemento muy importante, algo así como una tarjeta de presentación que debía invitar al lector a juzgar el libro por su cubierta, por lo que su llegada fue determinante para que estas alcanzaran su máxima expresión de radicalidad y sintonía con el diseño moderno.

La primera portada que abandonó cualquier tipo de referencia figurativa fue la del número de febrero de 1942 (figura 20), una composición cromática abstracta realizada por uno de los diseñadores gráficos más importantes de la historia del diseño moderno estadounidense: Alvin Lustig (Denver, Colorado, 1915 - Nueva York, 1955) (figura 21). Aquella portada de Lustig sentó las bases sobre el

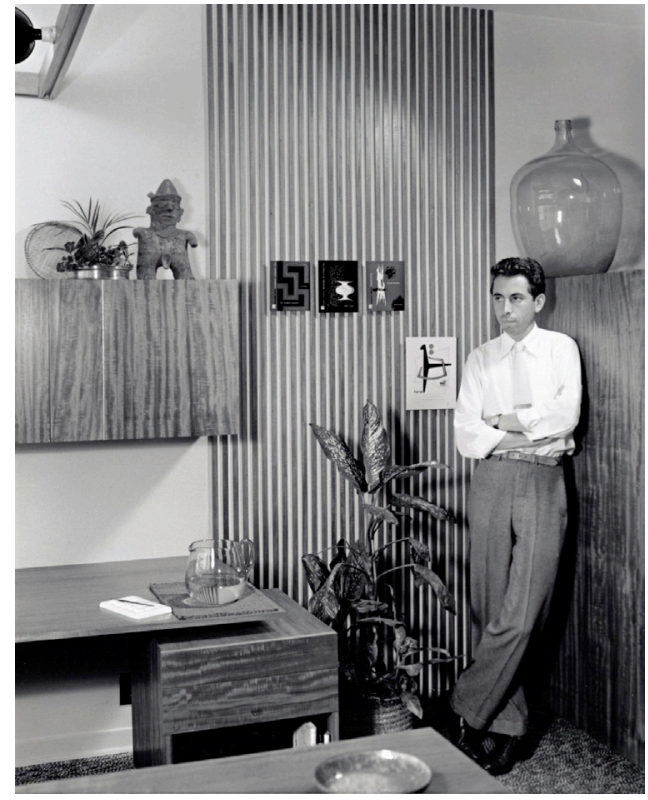

tipo de imagen que se quería transmitir en la portada, de tal manera que las composiciones abstractas de alto contenido artístico se convirtieron en la estrategia gráfica a perpetuar primero por Ray Eames, y posteriormente por el suizo Herbert Matter (Engelberg, Suiza, 1907 - Southampton, 1984) (figura 22), cuya llegada a Los Ángeles en 1943 tampoco pasó desapercibida para Entenza, quien cayó rendido ante su talento y pronto le atrajo a su órbita de influencia (Crosse 2010b). Matter diseñó la primera portada para California Arts $\&$ Architecture en mayo de 1944, dando inicio a un proceso de colaboración que le llevó a ser el autor de la mayoría de las portadas durante la segunda mitad de la década de 1940 (figura 23). Entenza premió su fidelidad inte-
Figura 20. Portada de California Arts \& Architecure del número de febrero de 1942, diseñada por Alvin Lustig.

Figura 21. Alvin Lustig (1915-1955) en su oficina de Los Ángeles, 1949.

Figura 22. Herbert Matter (1907-1984) en El Matador Beach, Malibú, hacia 1943.

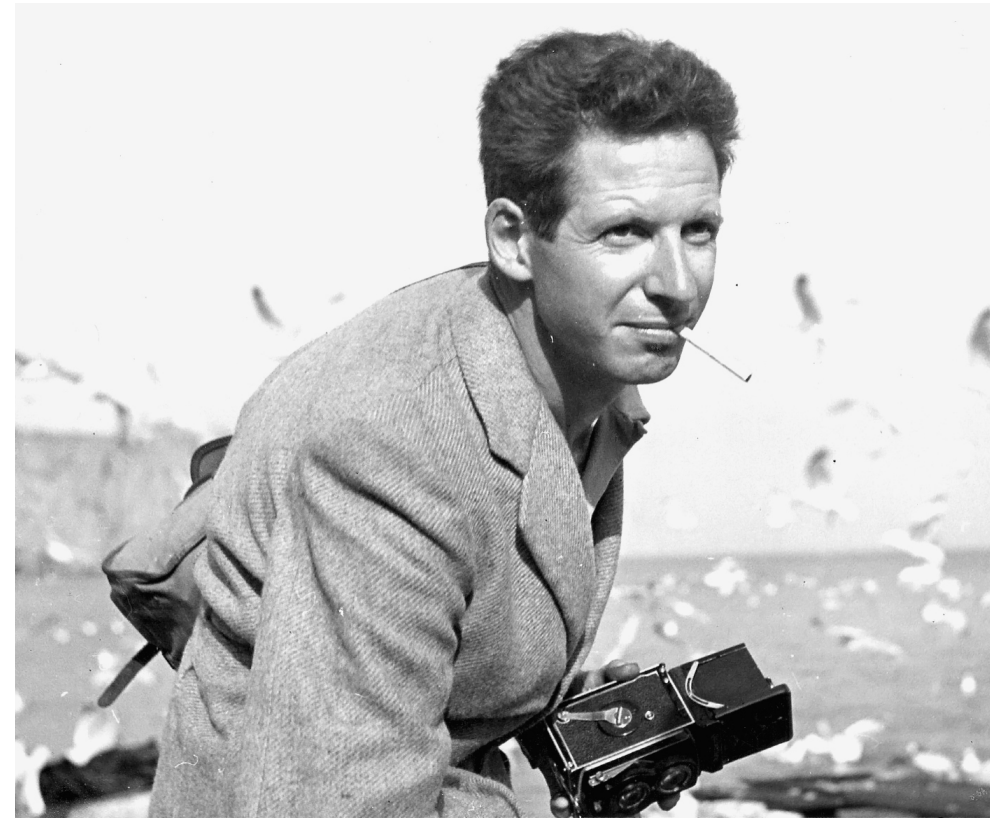


Figura 23. Algunas de las portadas que Herbert Matter diseñó para Arts \&

Architecture durante la segunda mitad de la década de 1940.
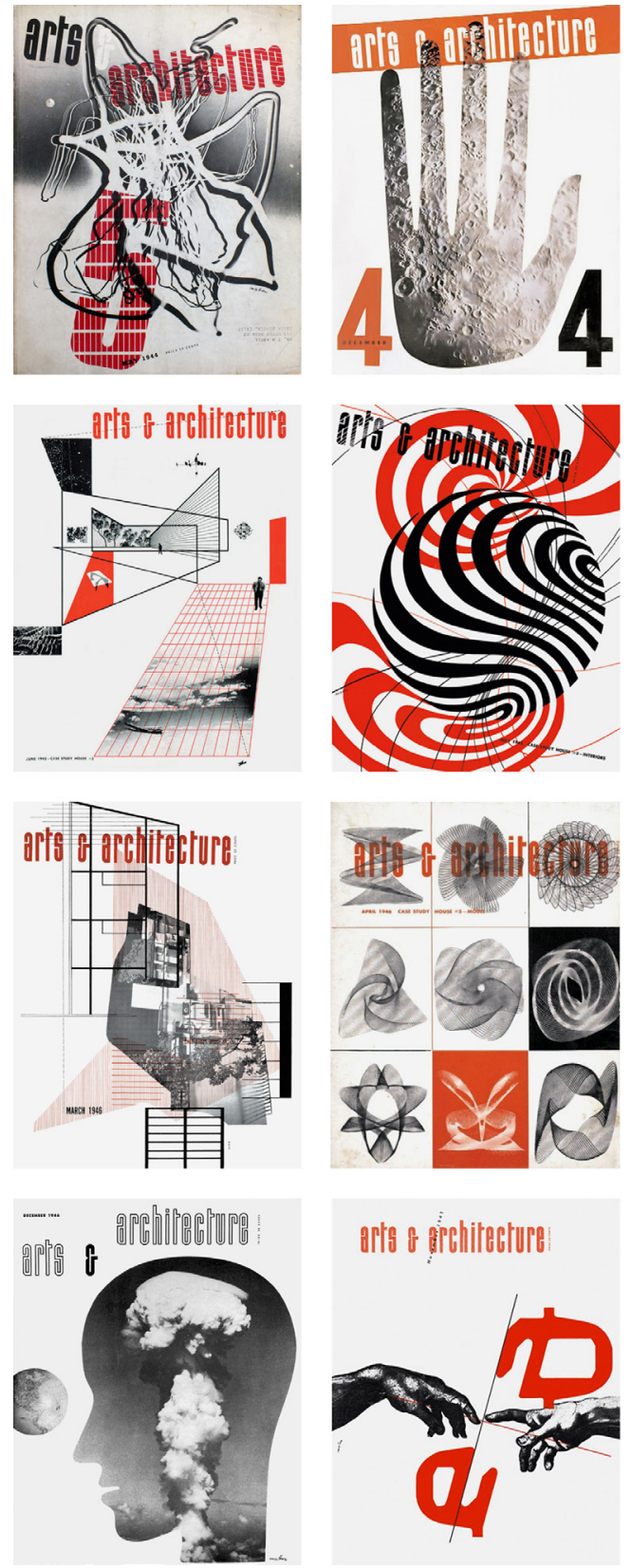

grándole en la plantilla de como miembro del Consejo Editorial desde el número de abril de 1946 y como socio editor desde septiembre de 1946. $^{11}$

Efectivamente, el número de febrero de 1942 constituyó un antes y un después en el desarrollo gráfico de California Arts \& Architecture. La portada de Alvin Lustig no se correspondía con un encargo aislado, sino que John Entenza lo había nombrado director artístico y le había dado plenos poderes para redefinir todo el concepto estético de su publicación. Lustig no ocultaba su excitación ante semejante encargo en una carta dirigida a James Laughlin, director de la editorial New Directions Books, para quien había diseñado muchas portadas de sus libros:
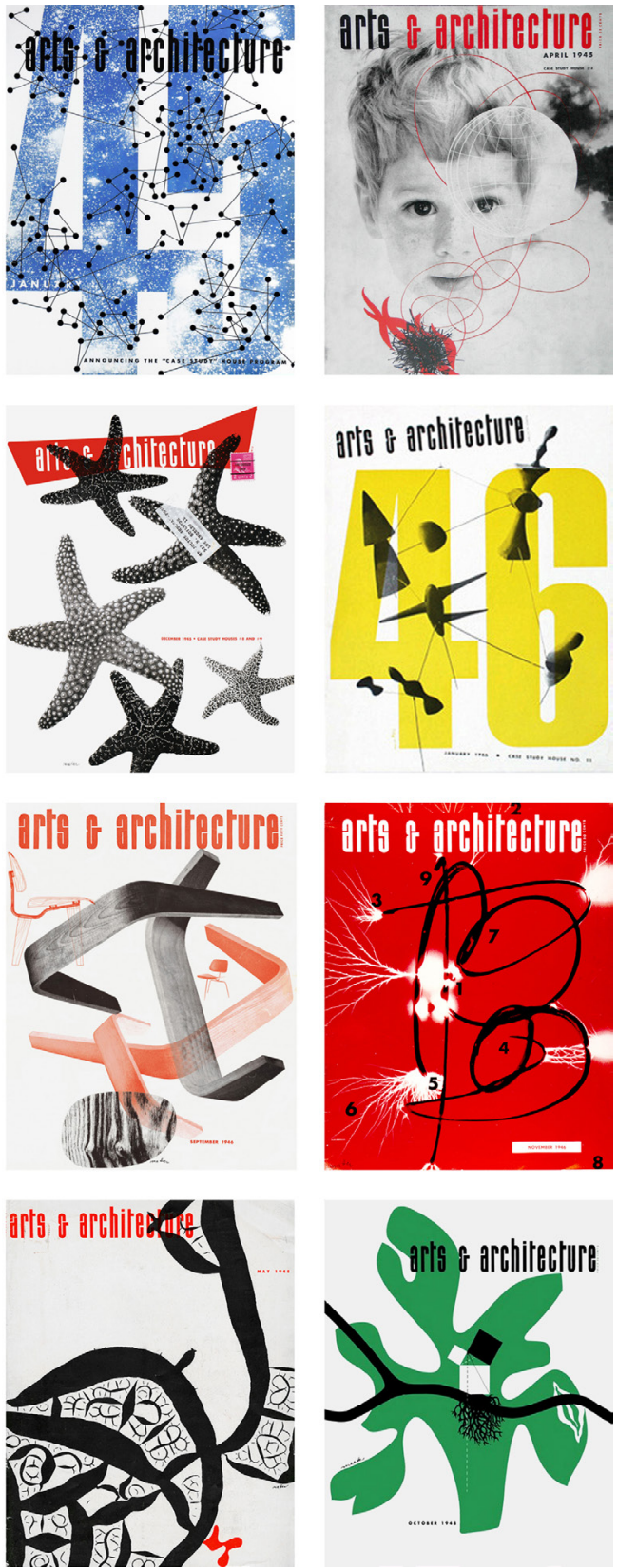

Me acaban de nombrar el director artístico de California Arts \& Architecture y me han concedido total libertad para hacer lo que quiera a nivel editorial [...]. Personalmente, creo que esta revista tiene potencial para convertirse en una de las más importantes que nunca se hayan publicado. (Heller y Lustig Cohen 2010: 76)

Lustig revolucionó California Arts \& Architecture: cambió las fuentes tipográficas del cuerpo del texto, rompió todas las convenciones de la maqueta interior, introdujo color y todo tipo de ilustraciones conceptuales para acompañar a los artículos y diseñó una nueva tipografía para la cabecera (figura 24) que ponía fin a un proceso de búsqueda de identidad que se remontaba hasta su propia fun- 
arts of archilectupe
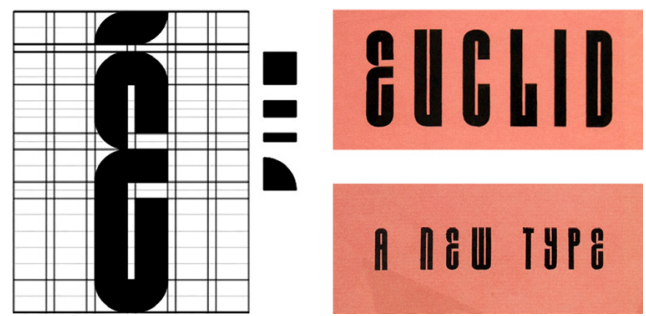

dación (figura 25). Un aspecto llamativo de la nueva cabecera era el cambio de letra y la sensible reducción del tamaño de la palabra "California" dentro del conjunto, que sería eliminada definitivamente dos años después, en el número de febrero de 1944. Esta decisión se orquestó como un movimiento de apertura que debía servir para que Arts \& Architecture abandonara su carácter estrictamente regional para convertirse en la plataforma ideal de explotación de un arte y una arquitectura que fueran representativos de los valores que se estaban incubando en Los Ángeles para proyectarlos a nivel mundial e internacional. Previamente, en el número de septiembre de 1943, un "accidente de impresión" había hecho que la palabra "California" no apareciera en portada, tal como narra David Travers:

La historia oficial es que se cayó del logotipo de la revista cuando la estaban imprimiendo y que nadie se dio cuenta. Así que en el número de septiembre de 1943 no estaba, pero volvió a aparecer el próximo mes. Mi teoría es que aquel 'accidente' fue ideado por el astuto director de publicidad, Robert Cron, que debía pensar que habría ventajas publicitarias si Arts \& Architecture adquiría un carácter más nacional. (Travers 2008)

Desafortunadamente, al igual que sucedería con los Eames, aquel idilio también fue breve. Los egos de Lustig y Entenza eran por completo incompatibles, así que en mayo de 1942, el diseñador abandonó su puesto. En opinión de Lustig, el problema era que

en el cielo no puede existir otra estrella al lado de la de John Entenza [...]. Sin embargo, he aprendido algo de todo esto. Hay que evitar siempre a todas esas personas que hacen grandes afirmaciones sobre su visión de futuro y que no paran de hablar de su dedicación a ello, ya que esa actitud suele esconder una tristísima muestra de vanidad y egoísmo. (Heller y Lustig Cohen 2010: 80)

A pesar de que la vinculación oficial de
Lustig duró solamente tres meses, ${ }^{12}$ el impacto que tuvo en Arts \& Architecture fue extraordinario. Aquel número de febrero de 1942 consolidó un producto editorial con una armonía estética que se mantendría intacta durante veinticinco años, hasta el final de la revista, en julio de 1967.

\section{Elegante como un Bugatti}

En enero de 1945, con la guerra virtualmente ganada, Arts \& Architecture anunció en su portada la puesta en marcha del programa Case Study House. El anuncio, más bien un manifiesto, de cinco páginas de extensión y firmado por Entenza, constituía una elocuente declaración de intenciones del programa en las cuales el editor jefe desgranaba las particularidades características de su propuesta. Aquel romántico llamamiento a la contemporaneidad tenía como firme objetivo investigar las posibilidades y posibles soluciones de la casa de la posguerra en California, "conce-
Figura 24. Nueva cabecera para California Arts \& Architecture (febrero de 1942) y experimentos tipográficos para la sintesis de 'Euclid. A New Type', por Alvin Lustig.
Figura 25. Evolución de la cabecera de California Arts \& Architecture, empezando por arriba: cabecera original (febrero de 1929 - enero de 1933); segunda cabecera, modificación de la original (febrero de 1933 - diciembre de 1935); tercera cabecera (enero de 1936 - febrero de 1940); cuarta cabecera, primera de la era Entenza (marzo de 1940 - mayo de 1940); quinta cabecera, segunda de la era Entenza (junio de 1940 - enero de 1942); sexta cabecera, tercera de la era Entenza, diseñada por Alvin Lustig (febrero de 1942 - enero de 1944); posteriormente se eliminaria la palabra "California", febrero de 1944 - julio de 1967).

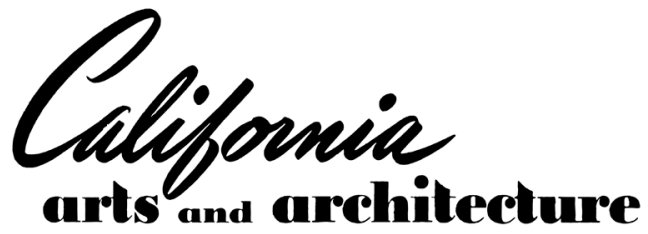

apts of archilecture 
bida dentro del espíritu de nuestro tiempo y adecuada a la expresión de la vida del hombre en el mundo moderno" (Entenza 1945: 39).

Hoy sabemos que aquel experimento arquitectónico reservaría a aquella pequeña revista de Los Ángeles un lugar importante en la historia de la arquitectura moderna del siglo XX. Sin embargo, es importante entender que esta iniciativa no era una ocurrencia aislada. Al contrario, significaba la materialización del compromiso que Entenza había mantenido intacto desde que asumió el mando en 1940 con el arte abstracto y con la arquitectura y el diseño modernos, que el editor entendia como una expresión natural del "buen gusto" y de los valores de una democracia moderna. Aquellos aspectos eran fundamentales para John Entenza, que "trataba el gusto como un tema que podia someterse a debate crítico, a la vez que mantenía una preocupación altruista por la elevación de sus estándares" (Votolato 1998: 54).

Así pues, la historia de John Entenza al frente de Arts \& Architecture pone de manifiesto que la evolución de la arquitectura no es solo cuestión de un cúmulo de circunstancias históricas, sino que también hechos y personas puntuales pueden alterar su curso significativamente. A ese respecto, el mayor acierto de Entenza fue el de saber seducir a una serie de artistas y diseñadores y reconducir su talento para dotar a su publicación de una identidad visual, intelectual y arquitectónica que resultó en una coreografia editorial cuya armonía gráfica y conceptual sirvió de plataforma a las vanguardias artísticas del movimiento moderno californiano de mediados del siglo XX. Su exquisita maquetación, la calidad de las imágenes y la potencia de sus portadas, en combinación con su apuesta por un aspecto y formato propios de una revista de diseño o de moda, la transformaron en un producto muy diferente al resto de publicaciones de arquitectura contemporáneas. Como bien resumiría Esther McCoy (1989: 16), aquella revista era "tan delgada como una tortilla [mexicana] y tan elegante como un Bugatti".

\section{Notas}

1 En el número de julio de 1929 la revista acortó su nombre al de The Architect and Engineer y en 1940 lo acortó aún más, pasando a llamarse, sencillamente, Architect and Engineer, titulo que mantendria hasta el cierre en 1956.

2 Hasta su desaparición en febrero de 1929, la revista tuvo diferentes nombres. Desde su fundación en 1911 hasta diciembre de 1914 se llamó The Pacific Coast Architect; a monthly journal for the architectural interests; entre los números de enero de 1915 y marzo de 1919 se llamó The Architect; desde abril de 1919 a diciembre de 1923 era Building Review; y en enero de 1924 volvió a su nombre original, Pacific Coast Architect.

3 La palabra "shelter" significa, literalmente, refugio. Aunque no está del todo claro, parece que los orígenes del término se encuentran en un artículo del New York Times publicado en julio de 1946, en el cual el periodista se refiere a la publicación Your Own Home como una "shelter magazine devoted to low-cost housing". Bold, Christine (ed.). 2012. The Oxford History of Popular Print Culture. Volume 6: US Popular Print Culture 1860-1920. Nueva York: Oxford University Press: 124-125.

4 La nómina completa de las viviendas publicadas incluía seis proyectos de Richard Neutra (Lovell Health House, VDL Research House, casa Koblick, casa Mosk, casa Beard y la casa StenFrenke), tres proyectos de Rudolph Schindler (casa Oliver, casa Gibling y casa Wolfe), y proyectos de Harwell Harris, J. R. Davidson, Kem Weber, Lloyd Wright, Jock Peters y del tándem Morrow \& Morrow. Ver California Arts \& Architecture, enero de 1935.

5 Durante algunos años, el subtítulo de la revista rezaba "crafts, decoration, gardens, life, music, drama", es decir, "artesanía, decoración, jardines, vida, música, teatro".

61938 es la fecha más ampliamente aceptada, que sostienen expertos en la materia como Esther McCoy, Barbara Goldstein, Elizabeth A. T. Smith y David Travers. Sin embargo, John Crosse apunta a que Entenza pudo hacerse con la revista algo más tarde. Crosse, John. 2010. " $\mathrm{Ca}$ lifornia Arts \& Architecture: A Steppingstone to Fame. Harwell Hamilton Harris and John Entenza". Southern California Architectural History, 31 de mayo: http://socalarchhistory.blogspot. com.es/2010/05/california-arts-architecture. html (visitado 23 feb. 2018).

7 Algunas fuentes apuntan a que todo fue bastante fortuito. Desde diciembre de 1936 y hasta el número de febrero de 1940, la editora jefe de California Arts \& Architecture era Jere B. Johnson. Johnson estaba embarazada y necesitaba a alguien para dirigir la revista temporalmente mientras estaba de baja por maternidad, asi que el arquitecto Harwell H. Harris le sugirió el nombre de John Entenza. GERMANY, Lisa. 1991. Harwell Hamilton Harris. Austin: University of Texas Press, 217.

8 Aquella cabecera duró solamente tres meses, hasta mayo de 1940. En el número doble de junio y julio de 1940, volvió a cambiarse a un diseño que se mantendría hasta febrero de 1942 , cuando se incorporó el diseño definitivo de Alvin Lustig, tal como se analizará más adelante.

9 Charles Eames apareció como miembro del Consejo Editorial desde el número de febrero hasta el de abril de 1942. En aquel momento, en el Consejo Editorial figuraban figuras populares de la arquitectura moderna californiana como William Wurster, Richard Neutra, Sumner Spaulding o Gregory Ain. Después, en mayo de 1942, Charles Eames fue ascendido en el escalafón de la revista a socio. 
10 Joseph Rosa cifra el número de edificios retratados por Shulman en unos doscientos cincuenta de los cerca de trescientos que construyó Neutra hasta su muerte en 1970 (Rosa 1994: 47).

11 Matter se mantendría como socio editor hasta el número de enero de 1964. A partir del número de febrero de 1964 y hasta el cierre de la revista, en julio de 1967, figuraba como miembro del Consejo Editorial.

12 Después de abandonar California Arts \& Architecture, Lustig siguió haciendo algunos trabajos de manera esporádica, entre los que destacan una serie de anuncios para la empresa de muebles H. G. Knoll que se publicarian en la revista entre 1944 y 1945, así como la portada del número de mayo de 1948.

\section{Bibliografia}

Albrecht, Donald. 1997. The work of Charles and Ray Eames: a legacy of invention. Nueva York: Harry N. Abrams in association with the Library of Congress and the Vitra Design Museum.

CA\&A. 1938. "A dwelling for Mr. John Entenza". California Arts \& Architecture, mayo de 1938 26-27.

CRosse, John. 2010. "California Arts \& Architecture: A Steppingstone to Fame. Harwell Hamilton Harris and John Entenza". Southern California Architectural History, 31 de mayo: http://socalarchhistory.blogspot.com.es/2010/05/california-arts-architecture.html (visitado $23 \mathrm{feb}$ 2018).

CRosse, John, 2010. "Herbert and Mercedes Matter: The California Years with the Eames Office and Arts \& Architecture". Southern California Architectural History, 19 de marzo: https://socalarchhistory.blogspot.com.es/2010/03/mercedes-and-herbert-matter-california.html (visitado 23 feb. 2018).

EAmes, Charles. 1941. "Design today". California Arts \& Architecture, septiembre de 1941: 14-15.

EAmes, Ray. 1943. "Ray Eames". California Arts \& Architecture, septiembre de 1943: 16-17.

Elwall, Robert. 2000. "Californian lifestyle". Architects' Journal, Vol. 212, No. 87, septiembre de 2000: 46-47.

EntenZA, John D. 1945. "The Case Study House Program". Arts \& Architecture, enero 1945: 37 41.

Germany, Lisa. 1991. Harwell Hamilton Harris. Austin: University of Texas Press.

Goldstein, Barbara (ed.). 1990. Arts \& Architecture: The Entenza Years. Cambridge: The MIT Press.

Heller, Steven y Lustig Cohen, Elaine. 2010. Born modern: the life and design of Alvin Lustig. San Francisco: Chronicle Books.

Kirkham, Pat. 1995. Charles and Ray Eames: designers of the twentieth century. Cambridge: The MIT Press.

Lubell, Sam y Woods, Douglas. 2011. Julius Shulman Los Angeles: The Birth of a Modern Metropolis. Nueva York: Rizzoli International Publications, 2011.

MatTer, Herbert; HeAd, Jeffrey y Hill, John T. 2005. Herbert Matter: modernist photography and graphic design. Stanford (California): Stanford University Libraries.
McCoy, Esther. 1984. The second generation. Salt Lake City: Peregrine Smith Books.

McCoy, Esther. 1989. "Arts \& Architecture Case Study Houses”. En Smith, Elizabeth A. T. (ed.), Blueprints for Modern Living: History and Legacy of the Case Study Houses. Cambridge: The MIT Press, 15-39.

Neuhart, John y NEuHart, Marilyn. 1989. Eames design: the work of the Office of Charles and Ray Eames. Nueva York: H.N. Abrams.

Oyer, George. 1935. "California - As we see it". California Arts \& Architecture, enero de 1935: 2.

RosA, Joseph. 1994. A Constructed View: The Architectural Photography of Julius Shulman. Nueva York: Rizzoli International Publications.

Schindler, Pauline. 1935. "Modern Architecture Acknowledges the Light Which Kindled It". California Arts \& Architecture, enero de 1935: 17.

Serraino, Pierluigi. 2004. Julius Shulman. Modernism Rediscovered. Colonia: Taschen.

Shulman, Julius. 1999. Julius Shulman: Architectu re and its Photography. Colonia: Taschen.

Smith, Elizabeth A. T. 1989. "Arts \& Architecture and the Los Angeles Vanguard". En Smith, Elizabeth A. T. (ed.), Blueprints for Modern Living: History and Legacy of the Case Study Houses. Cambridge: The MIT Press, 144-165.

TPCA. 1914. "Editorial - Special Announcement". The Pacific Coast Architect, Vol. VII, No. 1, marzo de 1914: 7 .

Thompson, Daniella. 2006. "Harris Allen: The Spirit of Individuality". The Berkeley Daily Planet 11 de Agosto: http://www.berkeleydailyplanet. com/issue/2006-08-11/article/24857?headline $=\mathrm{E}$ a s t $-\mathrm{B}$ a y $-\mathrm{T}$ he $\mathrm{n}-\mathrm{and}-\mathrm{Now}-\mathrm{H}$ a rris-Allen-The-Spirit-of-Individuality\&status=301 (visitado 23 feb. 2018).

Travers, David. 2008. "About Arts \& Architecture". http://www.artsandarchitecture.com/about. html (visitado 23 feb. 2018).

Vaught, Steve. 2011. "Beautiful Magazine Art - California Arts \& Architecture". Paradise Leased, 31 de julio: https://paradiseleased.wordpress. com/2011/07/31/beautiful-magazine-art-california-arts-ARCHITECTURE/ (visitado 23 feb. 2018).

Votolato, Gregory. 1998. American design in the twentieth century: personality and performance. Manchester y Nueva York: Manchester University Press.

VV.AA. 1998. L.A. Obscura: The architectural photography of Julius Shulman. Los Ángeles: Fisher Gallery, University of Southern California; edición en español: Los Ángeles Obscura: La fotografía arquitectónica de Julius Shulman. Valencia: Club Diario Levante, Universidad Politécnica de Valencia y Museo de la Universidad de Alicante.
Fecha final recepción artículos: 16/04/2018

Fecha aceptación: 22/06/2018

Artículo sometido a revisión por dos revisores independientes por el método doble ciego. 